Research Article

\title{
Coagulation of the Ionized Combustion Products in a Dust Flame of Aluminum Particles
}

\author{
N. I. Poletaev (iD and M. Y. Khlebnikova \\ Institute of Combustion and Advanced Technologies, Odessa I.I. Mechnikov National University, \\ 2 Dvoryanskaya St., Odessa 65082, Ukraine \\ Correspondence should be addressed to N. I. Poletaev; poletaev@ukr.net
}

Received 15 December 2018; Revised 28 March 2019; Accepted 11 April 2019; Published 27 June 2019

Academic Editor: Luqman C. Abdullah

Copyright ( $) 2019$ N. I. Poletaev and M. Y. Khlebnikova. This is an open access article distributed under the Creative Commons Attribution License, which permits unrestricted use, distribution, and reproduction in any medium, provided the original work is properly cited.

\begin{abstract}
The addition-agent effect of atoms of alkali metals (K, Na, $\mathrm{Li}$, and $\mathrm{Cs}$ ) and halogens ( $\mathrm{Cl}$ and $\mathrm{I}$ ) introduced into the combustion zone of a dust flame of aluminum particles on the average size of $\mathrm{Al}_{2} \mathrm{O}_{3}$ nanoparticles is studied. A physical model of coagulation of a monodisperse aerosol is proposed. The model takes into account the formation of a complex plasma consisting of positive and negative ions, electrons, neutral gas molecules, and suspended particles of the condensed phase in the combustion zone. The effect of the forces of Coulomb repulsion of unipolarly charged $\mathrm{Al}_{2} \mathrm{O}_{3}$ particles as well as their possible attraction by ion wind on the constant of the coagulation rate is also taken into account. It is shown that at low ion concentrations in the plasma, the coagulation rate is determined by the Coulomb repulsion of the particles, and at ion concentrations greater than $10^{20} \mathrm{~m}^{-3}$ the coagulation rate is determined by the attraction of the particles by the ion wind. The results of calculations of the dependence of the average $\mathrm{Al}_{2} \mathrm{O}_{3}$ particle size on the concentration of the additives are in a good quantitative agreement with the experimental data. The combined effect of the additives and the equilibrium products of aluminum oxide $\left(\mathrm{AlO}, \mathrm{Al}\right.$, and $\mathrm{Al}_{2} \mathrm{O}$ ) evaporation on the concentration of positive and negative gas ions, electrons, and $\mathrm{Al}_{2} \mathrm{O}_{3}$ particle size in the condensation zone is analyzed. The peculiarities of the influence of the additives of electronegative gases ( $\mathrm{Cl}$ and $\mathrm{I}$ atoms) on the coagulation rate of a thermally ionized aerosol and on the particle size of $\mathrm{Al}_{2} \mathrm{O}_{3}$ are considered.
\end{abstract}

\section{Introduction}

The widespread use of aluminum in aerospace technology as a high-energy additive to composite solid propellants explains the interest in studying the combustion of single aluminum particles and their gas suspensions in various oxidizers [1]. Currently, there are a number of studies devoted to the possibility of using aluminum in alternative energy, for example, for hydrogen production [2], or for energy generation in a metal-metal oxide-metal cycle $[2,3]$. Dust flames of aluminum particles are used to obtain powders of $\mathrm{Al}_{2} \mathrm{O}_{3}$ nanoparticles by the gas-disperse synthesis method (GDS) [4-6]. For all practical applications of aluminum combustion, it is important to control the physical, chemical, and dispersion properties of its combustion products. However, the physics and chemistry of the formation of condensed $\mathrm{Al}_{2} \mathrm{O}_{3}$ during aluminum combustion currently is far from complete understanding. The main problem that arises when analyzing the kinetic schemes for the formation of alumina is the lack of experimental confirmation of the existence of $\mathrm{Al}_{2} \mathrm{O}_{3}$ monomer molecules in the gas phase at combustion temperatures. In the literature, various ways to circumvent this problem are proposed. In some sources, the possibility of formation of $\mathrm{Al}_{2} \mathrm{O}_{3}$ molecules in the gas phase with a very short lifetime is allowed $[7,8]$. In this case, the nucleation kinetics can be described within the framework of the classical theory of homogeneous or heterogeneous nucleation. In other works, the formation of $\mathrm{Al}_{2} \mathrm{O}_{3}$ nuclei is substantiated by the results of quantum chemical and thermodynamic calculations, which indicate the possibility of the formation and growth of stable stoichiometric clusters $\left(\mathrm{Al}_{2} \mathrm{O}_{3}\right)_{n}(n=2 \div 75)[9,10]$. Another 
approach is based on the assumption of chemical condensation of aluminum suboxides $[6,11]$, as the main mechanism of condensed $\mathrm{Al}_{2} \mathrm{O}_{3}$ formation. In general, formation of $\mathrm{Al}_{2} \mathrm{O}_{3}$ in a gas phase is determined by stages of nucleation, surface growth of particles, and their coalescence and/or coagulation. Practically, depending on specific conditions, one of these stages may dominate; this greatly simplifies the description of the system's evolution. In [12], it was shown that the nucleation stage does not have a significant influence on the final dispersion of $\mathrm{Al}_{2} \mathrm{O}_{3}$ particles, which are formed during combustion of a gas suspension of aluminum particles in oxygen-containing environment at atmospheric pressure. This result is explained by the fact that in the diffusion flame of aluminum particles, nucleation proceeds in a nonbarrier mode and is extremely fast. The characteristic nucleation time is several orders of magnitude less than the characteristic heat-mass transfer times in the flame and the burning time of an aluminum drop. Moreover, according to [12], this condition is satisfied for both homogeneous ion-induced heterogeneous nucleation and chemical condensation. The high rate of nuclei formation leads to rapid depletion of monomers in the condensation zone and, as a consequence, to the cessation of the formation of new nuclei and the cessation of the surface growth of already formed nuclei due to addition of monomers. The main mechanism for the growth of nuclei under such conditions, as in the case of the synthesis of nanoparticles by burning or decomposing various precursors in the flame [13-15], is coagulation of $\mathrm{Al}_{2} \mathrm{O}_{3}$ particles [5, 16].

Thus, it can be assumed that the experimentally observed weak dependencies of the size of $\mathrm{Al}_{2} \mathrm{O}_{3}$ particles on concentration of fuel and oxidizer in the gas phase, size of aluminum particles, and type of carrier gas $[6,17,18]$ are a consequence of the weak influence of these parameters on the rate constant of coagulation of $\mathrm{Al}_{2} \mathrm{O}_{3}$ particles. Conversely, if the rate constant of aerosol particles coagulation is varied over a wide range, the size of the $\mathrm{Al}_{2} \mathrm{O}_{3}$ nanoparticles will also change quite strongly.

Previous studies have shown that the most promising way to control the size distribution of $\mathrm{Al}_{2} \mathrm{O}_{3}$ particles which are synthesized in aluminum dust flame is apparently a controlled thermal ionization of the combustion zone of a two-phase flame $[19,20]$. The effect of the flame ionization on the size of the combustion products is much stronger than the effect of the main parameters of the dust flame. It is well known that one of the effective ways to change the ionization degree of the flame is to introduce into the combustion zone atoms or molecules of chemical compounds that have a low ionization potential. This method of the flame ionization is actively used to control the distribution of soot particles [21] and other inorganic materials [22-24]. The ionization of the combustion zone of aluminum dust flame by introduction of additives of alkali metal atoms was successfully applied in $[19,20]$ to control the distribution of GDS-aluminum oxide. Obviously, the effectiveness of this way of the flame ionization is provided by high combustion temperatures of aluminum in oxygencontaining media $\left(T_{\mathrm{g}} \sim 2900-3300 \mathrm{~K}\right)$ [25].
In [19], it was experimentally shown that the dependence of the average particle size of $\mathrm{Al}_{2} \mathrm{O}_{3}$ on the concentration of easily ionizable potassium atoms is nonmonotonic (with a minimum). Later, an analogous dependence was obtained for the additives of cesium atoms to aluminum [20]. The increase in the concentration of alkali metal atoms in the flame leads first to a sharp decrease in the particle size of $\mathrm{Al}_{2} \mathrm{O}_{3}$, which reaches a minimum and then begins to increase with increasing concentration of ionizing additives. In general, the fuel may contain additives of both electronegative and electropositive atoms, the combined effect of which on the flame ionization and on the result of coagulation is practically not investigated.

At present, there are no physical models for the condensation of aluminum combustion products, which explain the experimental data obtained in $[19,20]$.

The aim of the present work is to analyze the effect of thermal ionization of a dust flame on the formation of condensed products of vapor-phase (or gas-phase) combustion of aluminum particles and to develop a physical model of coagulation of the ionized aerosol which would adequately describe the experimental results and allow prediction of effectiveness of application of various ionizing additives for control of the size distribution of the target products.

\section{Physical Model of Coagulation of Ionized Aerosol}

2.1. Experimental Background of the Model. Let us briefly discuss the experimental results obtained earlier, which were taken into account in the ionized aerosol coagulation model given below. Figure 1 shows the dependence of a particle size of aluminum oxides on a type of the ionizing additive and its concentration in the flame obtained in $[19,20]$.

In these studies, the synthesis of $\mathrm{Al}_{2} \mathrm{O}_{3}$ nanoparticles was performed in a laminar diffusion dust flame (LDDF) of aluminum particles $\left(d_{10}=4.8 \mu \mathrm{m}\right.$ in diameter), and their concentration in the flame was $C_{\mathrm{f}}=0.40 \pm 0.04 \mathrm{~kg} / \mathrm{m}^{3}$ $[5,6,26,27]$. The temperatures of gas $\left(T_{\mathrm{g}}=3200 \pm 100 \mathrm{~K}\right)$ and condensed $\left(T_{\mathrm{c}}=3150 \pm 150 \mathrm{~K}\right)$ phases in a combustion zone of such flame were previously measured by spectral methods [25, 28, 29]. Within the measurement error, these temperatures can be considered equal $\left(T_{\mathrm{g}} \approx T_{\mathrm{c}}\right)$. Aqueous solutions of alkali metal salts-potassium carbonate $\left(\mathrm{K}_{2} \mathrm{CO}_{3}\right)$, potassium chloride $(\mathrm{KCl})$, and cesium iodide (CsI)-were first added to the aluminum powder, then thoroughly mixed, and dried at the temperatures of $50-60^{\circ} \mathrm{C}$. The mass concentration of the additives was varied in the range $a_{\mathrm{S}}=0 \div 5 \mathrm{wt} . \%[19,20]$.

It was assumed $[19,20]$ that in the combustion zone of a dust flame at the temperature $T \sim 3000 \mathrm{~K}$, the metal salt completely thermally decomposes to the constituent atoms, and their concentration, in this case, is determined by using the following formula:

$$
n_{\mathrm{a}}=\frac{l \cdot a_{\mathrm{s}} C_{\mathrm{f}} N_{\mathrm{A}}}{\mu_{\mathrm{s}}} \cdot \frac{300}{T_{\mathrm{g}}},
$$




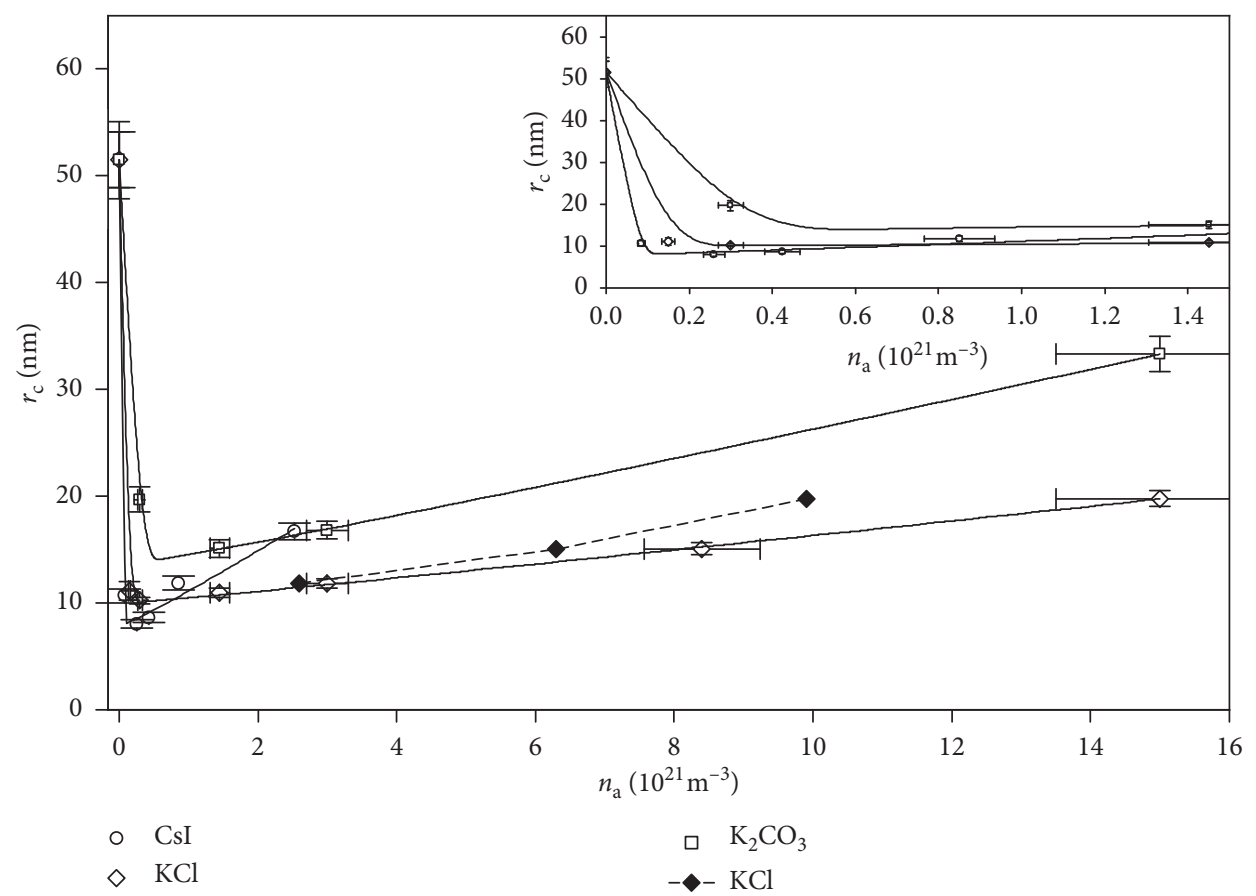

Figure 1: Dependence of the average radius of $\mathrm{Al}_{2} \mathrm{O}_{3}$ particles on the concentration of alkali metal atoms. Points: experiment; lines: approximation.

where $l$ is the number of metal atoms in a salt molecule (e.g., $l=2$ for $\mathrm{K}_{2} \mathrm{CO}_{3}$ ), $\mu_{\mathrm{s}}$ is the molecular weight of the salt, and $N_{\mathrm{A}}$ is the Avogadro constant. Estimates show that the effect of variation in the number of gas molecules in a salt decomposition reaction on the concentration of additives' atoms $n_{\mathrm{a}}$ in the mass concentration range $a_{\mathrm{S}}=0 \div 5 \mathrm{wt} . \%$ can be neglected. It is much more difficult to estimate the errors in determining the concentration of additives' atoms resulting from the incomplete decomposition of metal salts into atoms. Analysis of the equilibrium constants of the decomposition reactions of the thermally stable alkaline halides salts $\left(T_{\mathrm{g}}=3200 \mathrm{~K}\right)$ showed that for $\mathrm{KCl}, \mathrm{CsI}, \mathrm{NaCl}$, the assumption of practically complete dissociation of these molecules into atoms is acceptable for additives' concentrations $n_{\mathrm{a}}<(1.5-2.0) 10^{21} \mathrm{~m}^{-3}$ [30]. At higher concentrations of halides, it is necessary to take into account the degree of dissociation of additives' molecules into atoms. For example, for $n_{\mathrm{a}}=1.5 \cdot 10^{21} \mathrm{~m}^{-3}$, the degree of dissociation for the aforementioned halide molecules is $93-97 \%$, and for $n_{\mathrm{a}}=1.5 \cdot 10^{22} \mathrm{~m}^{-3}$, it decreases to $65-80 \%$. For $\mathrm{KCl}$, this leads to a noticeable change in the dependence of the particle size on the additives' concentration at $a_{\mathrm{S}}>1 \mathrm{wt} . \%$ (dashed curve in Figure 1).

If the additive molecules completely decompose into atoms, then according to (1), the error in the concentration of additives' atoms $n_{\mathrm{a}}$ in the combustion zone is determined primarily by the errors in determining the concentration of aluminum particles in the combustion zone of the dust flame and the gas temperature and does not exceed $15 \%$. The statistical error in determining the particle size of $\mathrm{Al}_{2} \mathrm{O}_{3}$ did not exceed $10 \%$.
The most correct approximation of the experimental dependences in Figure 1 was calculated by an asymmetric power function with powers $(p)$ for the descending and ascending branches of the dependence close to unity $(p=1.05 \div 1.2)$. It can be seen in Figure 1 that there is a sharp boundary of additives' concentration passing through the point of intersection of two "straight lines." This boundary separates different physical processes that determine the particle size of the combustion products in its concentration range of atoms of the additives. Our task was to identify and take into account these processes in the physical model of ionized aerosol coagulation.

\subsection{Main Assumptions and Governing Equations of the Model.} To build the model of condensation of the thermally ionized combustion products in a dust flame of aluminum particles, the following assumptions were made:

(1) We assume that microsized spherical aluminum particles $\left(d_{\mathrm{p}}<15 \mu \mathrm{m}, \quad C_{\mathrm{f}}=(0.20 \div 0.70) \mathrm{kg} / \mathrm{m}^{3}\right)$ are monodisperse and burn in the combustion zone of the dust flame in the diffusion mode (Figure 2). The particle number density (taking into account thermal expansion of the gas) of such flame is $n_{\mathrm{p}}=\left(\left(6 C_{\mathrm{f}}\right) /\right.$ $\left.\left(\pi d_{\mathrm{p}}^{3} \rho_{\mathrm{p}}\right)\right) \cdot\left(300 / T_{\mathrm{g}}\right)$. For example, for $d_{\mathrm{p}}=5 \mu \mathrm{m}$, $C_{\mathrm{f}}=0.40 \mathrm{~kg} / \mathrm{m}^{3}$, and $T_{\mathrm{g}}=3200 \mathrm{~K}$, the particle number density is $n_{\mathrm{p}}=2 \cdot 10^{11} \mathrm{~m}^{-3}$ and the distance between particles $\left(l_{\mathrm{p}} \sim\left(n_{\mathrm{p}}\right)^{-1 / 3}\right)$ is $l_{\mathrm{p}} \gg d_{\mathrm{p}}$. Thus, the combustion zones of the individual particles do not overlap, forming a microflame. This assumption was experimentally confirmed in $[4,28]$. 


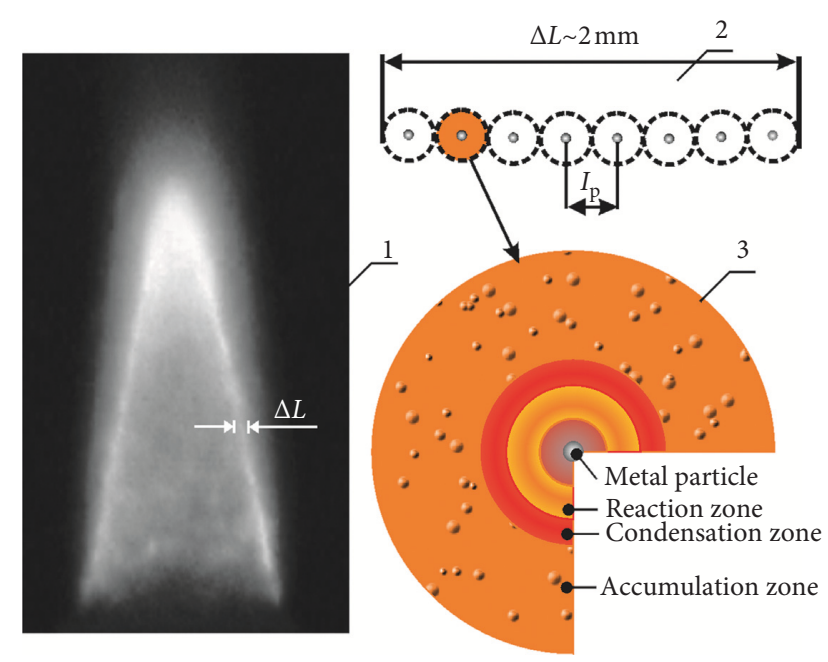

FIgURE 2: Structure of the combustion zone of the dust flame and microflame of an aluminum metal particle $\left(d_{\mathrm{p}}=4.8 \mu \mathrm{m}\right.$, $C_{\mathrm{f}}=0.4 \mathrm{~kg} / \mathrm{m}^{3}$ ) [12]. 1, laminar dust flame; 2, combustion zone; 3 , microflame structure.

(2) For monodisperse metal particles, their microflames can be assumed to be identical, and instead of analyzing the burning gas suspension of the particles, it is sufficient to consider simpler analysis of the burning single particles. It is convenient to assume that the volume of each microflame is equal to the volume per particle $V_{\mathrm{p}}=1 / n_{\mathrm{p}}$. The microflame has a complex zone structure-the zone of vapor-phase combustion, the zone of condensation, and the zone of accumulation of the condensed products of metal combustion (Figure 2) [12].

(3) It is assumed that the molecules of the combustion products (monomers) which are formed in the chemical reaction zone of the microflame have identical chemical composition as the condensate molecules. For aluminum, this assumption is used rather widely [31] despite the fact that gaseous $\mathrm{Al}_{2} \mathrm{O}_{3}$ was not experimentally found at the aluminum combustion temperatures.

To estimate the concentration of $\mathrm{Al}_{2} \mathrm{O}_{3}$ molecules in the combustion zone of the microflame $\left(n_{0}\right)$, we use the approximation of the infinitely thin diffusion front of combustion of metal vapors and oxygen: $n_{0}=\left(a_{\mathrm{ox}} \mu_{\mathrm{m}} P\right) /\left(\mu_{\mathrm{ox}} k_{\mathrm{B}} T_{\mathrm{g}}\right)$ [32]. Here, $a_{\mathrm{ox}}=\left(a_{\mathrm{p}} a_{\mathrm{O} 2}\right) /$ $\left(a_{\mathrm{p}} \xi_{\mathrm{O} 2}+a_{\mathrm{O} 2} \xi_{\mathrm{p}}\right), a_{\mathrm{p}}$ and $a_{\mathrm{O} 2}$ are the mass fractions of the combustion products in the front of the diffusion flame, metal vapors, and oxygen outside the vaporphase burning zone of a drop, respectively; $\xi_{\mathrm{p}}=\left(\nu_{\mathrm{p}} \mu_{\mathrm{p}}\right) /\left(\nu_{\mathrm{ox}} \mu_{\mathrm{ox}}\right)$ and $\xi_{\mathrm{O} 2}=\left(\nu_{\mathrm{o} 2} \mu_{\mathrm{o} 2}\right) /\left(\nu_{\mathrm{ox}} \mu_{\mathrm{ox}}\right)$ are the stoichiometric coefficients of the reaction $4 \mathrm{Al}+3 \mathrm{O}_{2}=2 \mathrm{Al}_{2} \mathrm{O}_{3} ; \quad \mu_{\mathrm{p}}, \quad \mu_{\mathrm{O} 2}, \quad \mu_{\mathrm{m}}=\left(\left(a_{\mathrm{ox}} / \mu_{\mathrm{ox}}\right)+\right.$ $\left.\left(a_{\mathrm{i}} / \mu_{\mathrm{i}}\right)\right)^{-1}, \mu_{\mathrm{ox}}$, and $\mu_{\mathrm{i}}$ are the molecular weights of aluminum, oxygen, the mixture of gaseous oxide and ballast gas, alumina, and ballast gas in the combustion zone of the microflame, respectively; $P$ is the pressure; and $k_{B}$ is the Boltzmann constant.
Since in the combustion zone the concentrations of fuel and oxidizer tend to zero, the mass fraction of the ballast gas in it will be close to $a_{\mathrm{i}} \approx 1-a_{\mathrm{ox}}$. For example, in the case of combustion of the gas suspension of aluminum particles in air $\left(a_{\mathrm{O} 2}=0.23\right)$ at atmospheric pressure and $T_{\mathrm{g}}=3200 \mathrm{~K}$, the value of $n_{0} \approx 3 \cdot 10^{23} \mathrm{~m}^{-3}$.

(4) We assume that the nucleation process is fast [12], and it is completed by the formation of the monodisperse stable nuclei with the initial concentration of $N_{0}=n_{0} / n_{\mathrm{cr}}$, where $n_{\mathrm{cr}}$ is the number of molecules of the monomer in the nucleus. If nucleation process is fast, the depletion of monomers in the condensation zone leads to the termination of new nuclei formation and the surface growth of previously formed liquid clusters of $\mathrm{Al}_{2} \mathrm{O}_{3}(l)$. Further growth of $\mathrm{Al}_{2} \mathrm{O}_{3}(l)$ nuclei during metal combustion determines the dispersion of the combustion products. In these conditions, the features of the nucleation mechanism (whether the condensation is homogeneous, heterogeneous ion-induced, or chemical) and the size of nuclei formed in this stage do not noticeably affect coagulation result [12].

For the microflame structure shown in Figure 2, $\mathrm{Al}_{2} \mathrm{O}_{3}$ nuclei formed at the initial moment of time will coagulate during the time $t_{\text {coag }}$, which is close to the burning time of the metal drop $t_{\mathrm{b}}$. For nuclei formed at the end of burning of the drop, coagulation time will be close to zero. That means that the characteristic size of the particles formed at the end of burning of the metal drop will depend on the radial coordinate of the microflame (1D spatial coordinate problem). In [16], the problem was solved under the assumption that all $\mathrm{Al}_{2} \mathrm{O}_{3}$ nuclei formed at the initial moment of time and have coagulated during the burning time of the metal drop (0D problem). Calculations have shown that the average particle size can differ markedly for $0 \mathrm{D}$ and $1 \mathrm{D}$ problems. However, this difference practically disappears if $t_{\text {coag }} \approx 1.5 t_{\mathrm{b}}$. Since the $\mathrm{Al}_{2} \mathrm{O}_{3}(l)$ particles are in the combustion zone of the dust flame for some time after burning the aluminum droplets and continue to coagulate, the condition $t_{\text {coag }}>t_{\mathrm{b}}$ is almost always satisfied. Based on these simplifications, we will consider coagulation in microflames in the 0D approximation.

(5) The experimental data for GDS nanooxides of metals indicate that particle size distributions are singlemode and narrow (coefficient of variation $(\mathrm{CV})$ is in the range of 30-70\%) [6]. Therefore, the dynamics of the change in the concentration of coagulating particles $N(t)$ can be determined in the monodisperse aerosol approximation:

$$
\frac{d N}{d t}=-\frac{1}{2} k \cdot N^{2}
$$

where $k$ is the coagulation rate constant. 
At the temperature $T_{\mathrm{g}}=3200 \mathrm{~K}$, the mean free path of molecules in gas is $l_{\mathrm{g}} \sim 700 \mathrm{~nm}$. For $\mathrm{Al}_{2} \mathrm{O}_{3}$ nanoparticles with a radius $r_{\mathrm{c}}<50 \mathrm{~nm}$, the strong inequality $l_{\mathrm{g}} \gg r_{\mathrm{c}}$ is satisfied, so the free-molecular approximation is applicable for the coagulation rate constant: $k=16 \cdot \pi$. $r_{\mathrm{W}}^{2} \cdot \sqrt{\left(k_{B} T_{\mathrm{g}}\right) /\left(\pi \cdot m_{\mathrm{g}}\right)} \cdot n^{1 / 6}[16]$, where $m_{\mathrm{g}}$ is the mass of the monomer molecule, $r_{\mathrm{W}}=\left(3 m_{\mathrm{g}} / 4 \pi \rho\right)^{1 / 3}$ is the Wigner-Zeits cell radius, $n=n_{0} / N$ is the number of $\mathrm{Al}_{2} \mathrm{O}_{3}$ molecules in an oxide particle, and $\rho$ is the density of the condensed phase. The radius of $\mathrm{Al}_{2} \mathrm{O}_{3}$ particles $\left(r_{\mathrm{c}}\right)$ is related to their concentration $(N)$ by the simple relation $r_{\mathrm{c}}=r_{\mathrm{W}}\left(n_{0} / N\right)^{1 / 3}$.

For charged aerosol particles, the coagulation rate constant $\left(k_{\mathrm{e}}\right)$ depends on the magnitude and sign of the charge of the particles and can be written as [33]

$$
k_{\mathrm{e}}= \begin{cases}k\left(1-\frac{U}{k_{B} T_{\mathrm{g}}}\right), & \operatorname{sign}\left(Z_{\mathrm{c} 1}\right) \neq \operatorname{sign}\left(Z_{\mathrm{c} 2}\right), \\ k \exp \left(-\frac{U}{k_{B} T_{\mathrm{g}}}\right), & \operatorname{sign}\left(Z_{\mathrm{c} 1}\right)=\operatorname{sign}\left(Z_{\mathrm{c} 2}\right),\end{cases}
$$

where $k$ is the constant of the uncharged particles coagulation rate, $U\left(R_{\min }\right)=\left(1 / 4 \pi \varepsilon_{0}\right)\left(\left(Z_{\mathrm{c} 1} Z_{\mathrm{c} 2} e^{2}\right) /\right.$ $\left.R_{\min }\right)$ is the energy of the electrostatic interaction of particles with charge numbers $Z_{\mathrm{c} 1}$ and $Z_{\mathrm{c} 2}, R_{\min }=2 r_{\mathrm{c}}$ is the minimum distance of approach of the particles, and $\varepsilon_{0}$ is the electric constant.

(6) We assume that the charges of the particles of the condensed phase have the same sign (either positive or negative), and the charge will be considered as an analogue quantity. The condition of applicability of the first assumption (as shown in [34]) is a unipolar charge distribution criterion: $\ln ^{2} p \geq 9 e^{2} /\left(2 \pi \varepsilon_{0} r_{\mathrm{c}} k_{B} T_{\mathrm{g}}\right)$ (where $p=\left(n_{\mathrm{i}} / n_{\mathrm{e}}\right) \sqrt{M_{\mathrm{e}} / M_{\mathrm{i}}}$ is the charge asymmetry factor, $n_{i}, M_{i}$ and $n_{e}, M_{e}$ are the concentration and mass of the ions (i) and electrons (e) in the gas phase). The fulfillment of the criterion $e^{2} /\left(4 \pi \varepsilon_{0} r_{c} k_{B} T_{\mathrm{g}}\right) \ll 1$ allows us to consider the charge of the particles as a continuous variable [34].

Thermal ionization of atoms and molecules of gases with a low ionization potential, as well as processes of thermoand photoelectron emission from the particle surface, leads to the appearance of electrons and positively charged ions in the microflame. The source of negative ions in the plasma is electronegative gases, whose molecules have a high-affinity energy $(\varepsilon)$ to electrons. For example, chlorine molecules $\left(\varepsilon_{\mathrm{Cl}}=3.61 \mathrm{eV}\right)$, iodine $\left(\varepsilon_{\mathrm{J}}=3.06 \mathrm{eV}\right)$, and aluminum suboxides $\mathrm{AlO}\left(\varepsilon_{\mathrm{AlO}}=2.6 \mathrm{eV}\right)$ and $\mathrm{AlO}_{2}\left(\varepsilon_{\mathrm{AlO}_{2}}=4.23 \mathrm{eV}\right)$ [35] can capture electrons, reducing their concentration in the gas phase. Estimates show that the contribution of aluminum particles and the ionization of nitrogen and oxygen molecules to the ionization equilibrium can be neglected [19]. For thermally ionized plasma, the temperatures of electrons $\left(T_{\mathrm{e}}\right)$, ions $\left(T_{\mathrm{i}}\right)$, and condensed plasma components $\left(T_{\mathrm{c}}\right)$ will be considered equal $\left(T_{\mathrm{e}}=T_{\mathrm{i}}=T_{\mathrm{c}}=T_{\mathrm{g}}\right)$. As was shown in [13], such complex plasma can be considered as Debye plasma.

Taking into account these assumptions, the average charge of the monodisperse particles can be determined as [36]

$$
Z_{\mathrm{c}}=\frac{4 \pi \varepsilon_{0} r_{\mathrm{c}} k_{B} T_{\mathrm{g}}}{e^{2}} \ln \left(\frac{n_{\mathrm{es}}}{n_{\mathrm{e}}}\right),
$$

where $n_{\mathrm{es}}=2 \cdot\left(\left(2 \pi m_{\mathrm{e}} k_{B} T_{\mathrm{g}}\right) / h^{2}\right)^{3 / 2} \exp \left(-\left(W /\left(k_{B} T_{\mathrm{g}}\right)\right)\right)$ is the equilibrium concentration of electrons near the particle surface of the oxide particle, $n_{\mathrm{e}}$ is the electron concentration in the interparticle space, $W$ is the work function of the electron, $m_{\mathrm{e}}$ is the mass of an electron, and $h$ is the Planck constant.

Under the assumption of the existence of a local thermodynamic equilibrium in the microflame, the concentration of charged components in the plasma can be estimated from the solution of $p+l+2$ equations of the ionization equilibrium:

$$
\left\{\begin{array}{l}
\frac{n_{\mathrm{e}} n_{i p}^{+}}{\left(n_{a p}-n_{i p}^{+}\right)}=\frac{2 g_{i p}}{g_{a p}} \nu_{\mathrm{e}} \exp \left(-\frac{I_{p}}{k_{B} T_{\mathrm{g}}}\right), \\
\frac{n_{\mathrm{e}}\left(n_{a l}-n_{i l}^{-}\right)}{n_{i l}^{-}}=\frac{2 g_{a l}}{g_{i l}} \nu_{\mathrm{e}} \exp \left(-\frac{\varepsilon_{l}}{k_{B} T_{\mathrm{g}}}\right), \\
Z_{\mathrm{c}}=\frac{4 \pi \varepsilon_{0} r_{\mathrm{c}} k_{B} T_{\mathrm{g}}}{e^{2}} \ln \left(\frac{n_{\mathrm{es}}}{n_{e}}\right) \\
n_{\mathrm{e}}=\sum_{p} Z_{i p} n_{i p}+\sum_{l} Z_{i l} n_{i l}+Z_{\mathrm{c}} n_{\mathrm{c}}
\end{array}\right.
$$

where $n_{a p}$ is the concentration of atoms of electropositive gases ( $p=\mathrm{K}, \mathrm{Cs}, \mathrm{Li}, \mathrm{Al}, \mathrm{Na}$, etc.), $n_{a l}$ is the concentration of atoms of electronegative gases $\left(l=\mathrm{Cl}, \mathrm{I}, \mathrm{AlO}, \mathrm{AlO}_{2}\right.$, etc.), $n_{i p}^{+}$ and $n_{i l}^{-}$are the concentrations of positive and negative ions, $I_{p}$ and $\varepsilon_{l}$ are the ionization potentials of $p$-atoms and the electron affinity of $l$-atoms, $g_{i p}$ and $g_{i l}$ are the degrees of degeneracy for ions, $g_{a p}$ and $g_{a l}$ are the degrees of degeneracy for atoms of the ionizing additive, $Z_{i p}, Z_{i l}$ are the charge numbers of positive $\left(Z_{i p}>0\right)$ and negative ions $\left(Z_{i l}<0\right)$, and $n_{\mathrm{c}}$ is the concentration of $\mathrm{Al}_{2} \mathrm{O}_{3}$ particles. The first $p$ equations and the subsequent $l$ equations of system (5) are Saha equations for ionization of atoms of electropositive and electronegative gases, respectively. The last two equations of the system for the charge numbers of particles $\left(Z_{\mathrm{c}}\right)$ and the quasineutrality equation complete the system of equation (5). In the calculations, it was assumed that the ions of the gas phase were singly ionized $\left(Z_{i p}=1\right.$ and $\left.Z_{i l}=-1\right)$. The ratios of the degrees of degeneracy were taken to be unity.

Analysis of the experimental data shown in Figure 1 allows us to conclude that the coagulation model must take into account not only the Coulomb repulsion of like-charged particles but also the possibility of their attraction. In physics of dusty plasma, there are several different mechanisms that can lead to the attraction of equally charged particles in a 
quasineutral plasma: the shadow (or Le Sage) attraction of dust particles $[37,38]$, the attraction of like-charged particles due to the collective effects in dusty plasma [39], and recombination forces [40]. After analyzing the mentioned mechanisms given in [19], we have included a polarization mechanism of the interaction of particles in the model of coagulation in the microflame. A detailed description this mechanism is given in [33].

To take into account the polarization interaction of the charged particles, an effective interaction potential $V(r)=$ $-\chi|U(r)|$ was introduced, where the parameter $\chi$ describes the plasma contribution to the pair interaction [33]:

$$
\chi=\left(\frac{Z_{\mathrm{i}} n_{\mathrm{i}}(1-S)}{Z_{\mathrm{c}} N_{\mathrm{c}}}\right)^{2}\left(\frac{r_{\mathrm{c}}}{r_{\mathrm{c}}^{*}}-1\right),
$$

where $S=n_{\mathrm{e}} / n_{\mathrm{i}}, n_{\mathrm{i}}, n_{\mathrm{e}}$ is the ion and electron concentrations far from the particle, $Z_{\mathrm{i}}$ and $Z_{\mathrm{c}}$ is the charge numbers of ions and particles, $r_{\mathrm{c}}^{*}=\sqrt{\left(n_{\mathrm{b}} \sigma_{0}(1-S)\right) /\left(\pi N_{\mathrm{c}}\right)} \sqrt{\zeta} \exp (-(1 / 2 \zeta))$, $\sigma_{0}$ is the cross section of the interaction of ions with neutral gas atoms, and $n_{\mathrm{b}}$ is the concentration of neutral gas atoms. The parameter $\zeta \approx\left(4 \pi \varepsilon_{0} k_{B} T_{\mathrm{g}} r_{\mathrm{c}}\right) /\left(\left|Z_{\mathrm{c}}\right| e^{2}\right)$ describes the kinetic energy of ions in the field of the charged particle.

After including the electrostatic and polarization interactions, the coagulation rate constant $\left(k_{e p}\right)$ becomes [33]

$$
k_{e p}= \begin{cases}k\left(1-\frac{V}{k_{B} T_{\mathrm{g}}}\right), & x \geq 0, \\ k \exp \left(-\frac{V}{k_{B} T_{\mathrm{g}}}\right), & x<0 .\end{cases}
$$

If the radius of the particle $r_{c}$ is less than a certain critical radius $\left(r_{\mathrm{c}}^{*}\right)$, then $\chi$ is negative and, according to (7), the coagulation rate constant decreases exponentially with increasing $|U(r)| /\left(k_{B} T_{\mathrm{g}}\right)$. However, if the particle size exceeds the critical value $\left(r_{\mathrm{c}}>r_{\mathrm{c}}^{*}\right)$, then $\chi>0$ and the coagulation rate of the charged particles begins to increase.

When the plasma contains the ions of different signs (for example, potassium and chlorine ions), the forces of plasma streams directed to the opposite sides of the particle surface will be partially compensated depending on the ion concentration and their charge and mass. We will neglect the difference in the ion masses, and their concentration $\left(n_{\mathrm{i}}\right)$ in (6) will be determined as the algebraic sum $j$ of the concentrations $\left(n_{i j}\right)$ of different ions $n_{\mathrm{i}}=\left|\sum_{j} Z_{i j} n_{i j}\right|$ (the sign of $Z_{i j}$ is determined by the sign of the ion charge).

Time integration of equation (2) with the coagulation rate constant (3) or (7) and with the system of ionization equilibrium equations (5) was performed to the time value $t_{\mathrm{b}}=4 \cdot 10^{-3} \mathrm{~s}$ (the burning time of the aluminum particle with the diameter $d_{\mathrm{p}}=4.8 \mu \mathrm{m}$ [16]). The initial condition $N_{0}(t=0)=n_{0} / n_{\text {cr }}$ for (2) was used. Preliminary calculations have shown that the size of the critical nuclei $n_{\text {cr }}$ practically does not affect the particle size of $\mathrm{Al}_{2} \mathrm{O}_{3}$; therefore, all calculations were performed at the fixed value of $n_{\mathrm{cr}}=100$.

\section{Results and Discussion}

Next, we focus our attention on the analysis of the effect of addition-agent type and concentration on the characteristic particle size of aluminum oxide.

3.1. Coulomb Interaction of Particles in the Coagulating Aerosol. Let us analyze the effect of the concentration of the ionizing additives on the particle size of $\mathrm{Al}_{2} \mathrm{O}_{3}$ with taking into account only their Coulomb interaction (equation (2) with the coagulation rate constants (3)). Without the atoms of easily ionizable additives or at their low concentration $\left(n_{\mathrm{a}}<10^{18}-10^{19} \mathrm{~m}^{-3}\right)$, a thermionic electron-dust plasma consisting of electrons and positively charged particles of the condensed phase formed in the microflame. The quasineutrality equation for such plasma is $n_{\mathrm{e}} \approx Z_{\mathrm{c}} n_{\mathrm{c}}$, and the particle charge is determined from the solution of the transcendental equation (4). For thermionic plasma, an analysis of the influence of particle charge on the rate of their coagulation was performed in [16].

In fact, the existence of purely thermionic electron-dust plasma in the condensation zone is unlikely. This is due to the fact that in addition to emission processes, natural impurities which are practically always present in the initial aluminum powder and ionization of the products of aluminum oxide equilibrium evaporation in the condensation zone also affect the ionization of the microflame. The main products of evaporation of $\mathrm{Al}_{2} \mathrm{O}_{3}(l)$ are $\mathrm{Al}$ atoms and $\mathrm{AlO}$ and $\mathrm{AlO}_{2}$ molecules. For example, at the temperature $T_{\mathrm{g}}=3200 \mathrm{~K}$ and atmospheric pressure, the concentrations of these gases in an inert mixture of nitrogen and $\mathrm{Al}_{2} \mathrm{O}_{3}(l)$ are $n_{\mathrm{Al}}=5 \cdot 10^{21} \mathrm{~m}^{-3}$, $n_{\mathrm{AlO}}=6 \cdot 10^{21} \mathrm{~m}^{-3}$, and $n_{\mathrm{AlO}_{2}}=5 \cdot 10^{21} \mathrm{~m}^{-3}$ [41]. Moreover, taking into account the influence of size effects on the saturated vapor pressure at the surface of $\mathrm{Al}_{2} \mathrm{O}_{3}$ nanoparticles, these concentrations can be higher than the aforementioned values. The evaporation of $\mathrm{Al}_{2} \mathrm{O}_{3}$ particles in an oxidizing medium leads to the opposite effect-a decrease in the concentration of aluminum vapor and aluminum suboxides.

Calculations have shown that the aluminum vapor has the strongest effect on the ionization equilibrium in plasma. This can be explained by the relatively low ionization potential of aluminum atoms $\left(I_{\mathrm{Al}}=5.99 \mathrm{eV}\right)$. The appearance of aluminum ions $\left(n_{\mathrm{Al}}^{+}\right)$changes the electron-dust plasma into the complex one $\left(n_{\mathrm{e}} \approx Z_{\mathrm{c}} n_{\mathrm{c}}+n_{\mathrm{Al}}^{+}\right)$and affects the charge and particle size of $\mathrm{Al}_{2} \mathrm{O}_{3}$. It is important to note that despite the high-affinity energy for the molecules of $\mathrm{AlO}$ and $\mathrm{AlO}_{2}$ $\left(\varepsilon_{\mathrm{AlO}}=2.60 \mathrm{eV}, \varepsilon_{\mathrm{AlO}_{2}}=4.23 \mathrm{eV}\right)$, the effect of their ionization on $\mathrm{Al}_{2} \mathrm{O}_{3}$ particle size, in contrast to aluminum vapor, can be neglected. The concentrations of aluminum atoms less than $10^{18} \mathrm{~m}^{-3}$ (equivalent to $n_{\mathrm{Al}}=0$ ) also do not affect the results of calculations.

The ionization of aluminum vapor affects the size and electric charge of $\mathrm{Al}_{2} \mathrm{O}_{3}$ particles only at low concentrations of ionizing additives, which have a lower ionization potential than aluminum, or their absence. For example, for potassium at concentrations $n_{\mathrm{K}}>10^{20} \mathrm{~m}^{-3}$ and $T_{\mathrm{g}}=3200 \mathrm{~K}$, aluminum atoms in the concentration range $n_{\mathrm{Al}}=10^{18} \div 10^{22} \mathrm{~m}^{-3}$ 
practically do not affect the charge and particle size of $\mathrm{Al}_{2} \mathrm{O}_{3}$ (Figure 3). For $n_{\mathrm{K}}<10^{20} \mathrm{~m}^{-3}$, the form of dependences $1-3$ is determined by the combined effect of both electropositive gases $(\mathrm{Al}$ and $\mathrm{K})$ on the ionization equilibrium in plasma. Curve $1\left(n_{\mathrm{Al}}=10^{18} \mathrm{~m}^{-3}\right)$ has a maximum particle size at the concentration of potassium atoms $n_{\mathrm{K}} \approx 3.4 \cdot 10^{19} \mathrm{~m}^{-3}$, which corresponds to a mass fraction of potassium carbonate in the fuel $a_{\mathrm{S}} \sim 0.01 \%$ (see the inset in Figure 3). For this concentration of the additive, the charge of $\mathrm{Al}_{2} \mathrm{O}_{3}$ particles is close to zero and the coagulation rate constant (3) has a maximum value $\left(k_{\mathrm{e}}=k\right)$. An increase in the concentration of aluminum vapor $\left(n_{\mathrm{Al}}>10^{18} \mathrm{~m}^{-3}\right)$ is followed by a decrease in the positive charge of $\mathrm{Al}_{2} \mathrm{O}_{3}$ particles, a change of the charge sign to negative $\left(n_{\mathrm{Al}}>10^{21} \mathrm{~m}^{-3}\right)$, and an increase in this charge.

The effect of electropositive and electronegative atoms on the dependences of the particle size on the concentration of these atoms is shown in Figure 4(a). Calculations were performed at the gas temperature $T_{\mathrm{g}}=3200 \mathrm{~K}$ and at the equilibrium concentration of aluminum atoms for this temperature $n_{\mathrm{Al}}=5 \cdot 10^{21} \mathrm{~m}^{-3}$. For alkaline metals, Cs, $\mathrm{K}, \mathrm{Na}$, and $\mathrm{Li}$ ( $\mathrm{Li}$ is not shown in the graph because of a slight difference from $\mathrm{Na}$ ), for small $n_{\mathrm{a}}$, the particle size of $\mathrm{Al}_{2} \mathrm{O}_{3}$ drops sharply, while for larger $n_{\mathrm{a}}$ values, the dependence yields a very weak one. These calculations are similar to the experimental dependences in Figure 1. The insert in Figure 4(a) shows these dependences on a logarithmic scale. The rates of change in the particle size $\left(d r_{\mathrm{c}} / d n_{\mathrm{a}}\right)$ are arranged in order of increasing ionization potential of alkali metal atoms $\left(I_{\mathrm{Cs}}=3.89 \mathrm{eV}, I_{\mathrm{K}}=4.34 \mathrm{eV}, I_{\mathrm{Na}}=5.14 \mathrm{eV}, I_{\mathrm{Li}}=\right.$ $5.39 \mathrm{eV}$ ). The minimum particle size at the concentration $n_{\mathrm{a}}=10^{23} \mathrm{~m}^{-3}$ increases from 3 to $6 \mathrm{~nm}$ in the same sequence.

The presence of electronegative atoms in the additives' molecules ( $\mathrm{KCl}$, CsI, and $\mathrm{NaCl}$ ) leads to weakening of the dependence $r_{\mathrm{c}}=f\left(n_{\mathrm{a}}\right)$ (dashed lines in Figure 4(a)) in comparison with the corresponding dependence for the alkali metals $\mathrm{K}, \mathrm{Cs}$, and Na. The greater the ionization potential of metal atoms, the stronger the influence of electronegative atoms ( $\mathrm{Cl}$ and $\mathrm{I})$ on the dependence $r_{\mathrm{c}}=f\left(n_{\mathrm{a}}\right)$.

The weaker effect of the additives' concentration on the particle size of $\mathrm{Al}_{2} \mathrm{O}_{3}$ (Figure 4(a)) is related to the nontrivial dependence of the particle charge on the additives' concentration (Figure 4(b)). The nonmonotonic nature of this dependence and the position of the minimum are determined by the transcendental equation (4) for the charge numbers $Z_{\mathrm{c}}$. The electron concentration $\left(n_{\mathrm{e}}\right)$ in $(4)$ is a complex function of the ion concentration, the concentration and the charge number of $\mathrm{Al}_{2} \mathrm{O}_{3}$ particles, and is determined by the solution of the system equations (5).

As it follows from the discussion of Figures 4(a) and 4(b), taking into account only the Coulomb interaction of the coagulating particles does not allow us to explain the results of the experimental studies shown in Figure 1.

3.2. Effect of Coulomb and Polarization Interactions in the Ionized Aerosol. Now consider the joint effect of the electrostatic and polarization interactions of the charged particles on the aerosol's coagulation. The dependences $r_{\mathrm{c}}=f\left(n_{\mathrm{a}}\right)$ for the additives shown in Figure 5 were obtained by solving equation (2) with the coagulation rate constant (7). Let us to compare the calculation results shown in Figures 4 and 5 . We can see that taking into account the contribution of the plasma to the pair interaction of the coagulating particles (see equations (6) and (7)) practically does not affect the behavior of these dependences in the region of low concentrations of impurity atoms and substantially changes them in the region of higher impurity concentrations. For $\mathrm{K}_{2} \mathrm{CO}_{3}, \mathrm{KCl}$, and CsI additives (curves 1, 2 , and 3 in Figure 5), qualitative agreement with the experimental data is observed (curves 1, 2, and 3 in Figure 1). For $\mathrm{NaCl}$ and $\mathrm{LiCl}$ additives (curves 4 and 5 in Figure 5), there is no minimum, and the dependence of the particle size on the concentration is relatively weak. This is due to a higher work function of electrons from these metals in comparison with $\mathrm{Cs}$ and $\mathrm{K}$ and, as a consequence, to a low degree of ionization of the gas at combustion temperatures.

Coulomb repulsion of particles in aerosols leads to a decrease in their size, while the forces of ion entrainment of particles lead to their coarsening. The competition between these two mechanisms determines the minimum allowable particle size $\left(r_{\mathrm{c}}>15 \mathrm{~nm}\right)$ larger than in the case of considering only the Coulomb interaction $\left(r_{\mathrm{c}}=3 \div 5\right) \mathrm{nm}$.

The strongest parameter affecting the ionization of a two-phase medium is temperature. The temperature variation in the microflame does not lead to a qualitative change in the calculated dependences (Figure 6). However, the temperature has a strong effect on the minimum particle size of $\mathrm{Al}_{2} \mathrm{O}_{3}$, which decreases by almost a half when the gas temperature decreases from $T_{\mathrm{g}}=3200 \mathrm{~K}$ to $T_{\mathrm{g}}=2800 \mathrm{~K}$ (Figure 6). Curves 1-3 in Figure 6 were obtained by taking into account the dependence of the equilibrium concentration of aluminum vapor on the temperature. The combustion temperature of the dust flame of aluminum particles is strongly affected by the concentrations of fuel and oxygen $[28,29]$. Therefore, it should be expected that the variation of these gas suspension parameters in the presence of alkali metals in the flame will have a significant effect on the size distribution of the $\mathrm{Al}_{2} \mathrm{O}_{3}$ particles.

In the proposed coagulation model of the like-charged particles $\left(\mathrm{Al}_{2} \mathrm{O}_{3}\right)$, the coagulation rate is determined by the competition between the forces of Coulomb repulsion $\left(F_{c}\right)$ of particles and their attraction by ion wind $\left(F_{\mathrm{i}}\right)$ forces. Since both forces are proportional to the electric field $E$ produced by the $\mathrm{Al}_{2} \mathrm{O}_{3}$ particles [19], it is convenient to analyze the ratio $R=F_{\mathrm{i}} / F_{\mathrm{c}}$ as a criterion of changing the coagulation regime, which does not depend on the electric field strength. If $R<1$, then the decrease in the coagulation rate and particle size is determined by their Coulomb repulsion. If $R>1$, then the increase in the coagulation rate is determined by the ionic wind, which rises with an increase in the concentration of ions in the gas. According to [19], $R\left(n_{\mathrm{i}}, n_{\mathrm{n}}, r_{\mathrm{c}}\right)=\left(\left(8 \sqrt{\pi} r_{\mathrm{c}}^{2} n_{\mathrm{i}}\right) /\left(3 n_{\mathrm{n}} \sigma_{\mathrm{in}} Z_{\mathrm{c}}\right)\right)\left(1+\left(\rho_{0} / 2 r_{\mathrm{c}}\right)\right)$, where $\rho_{0}=\left(1 /\left(4 \pi \varepsilon_{0}\right)\right)\left(\left(\left|Z_{\mathrm{c}}\right| e^{2}\right) /\left(m_{\mathrm{i}} v_{T i}^{2}\right)\right)$ is the parameter that characterizes Coulomb scattering of ions on $\mathrm{Al}_{2} \mathrm{O}_{3}$ particles, $m_{\mathrm{i}}$ and $n_{\mathrm{i}}$ are the ion mass and ion concentration, $n_{\mathrm{n}}$ is the concentration of neutral atoms, $v_{T i}=\sqrt{3 k_{B} T_{\mathrm{g}} / \pi m_{\mathrm{i}}}$ is the ion thermal velocity, $\sigma_{\text {in }}$ is the collision cross section of ions with 


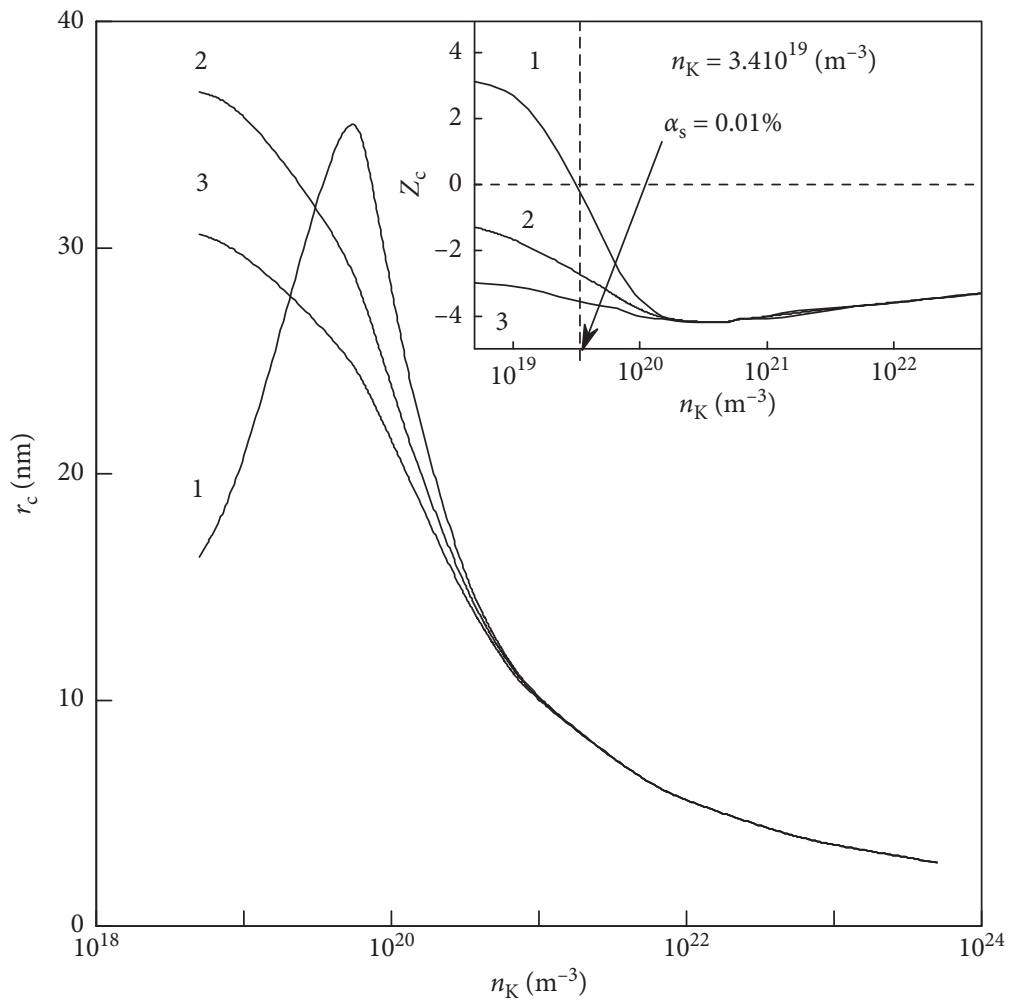

FIGURE 3: Dependence of $\mathrm{Al}_{2} \mathrm{O}_{3}$ particle radius on the concentration of potassium atoms for different concentrations of aluminum atoms $\left(T_{\mathrm{g}}=3200 \mathrm{~K}\right) .1, n_{\mathrm{Al}}=10^{18} \mathrm{~m}^{-3} ; 2, n_{\mathrm{Al}}=5 \cdot 10^{21} \mathrm{~m}^{-3} ; 3, n_{\mathrm{Al}}=10^{22} \mathrm{~m}^{-3}$.

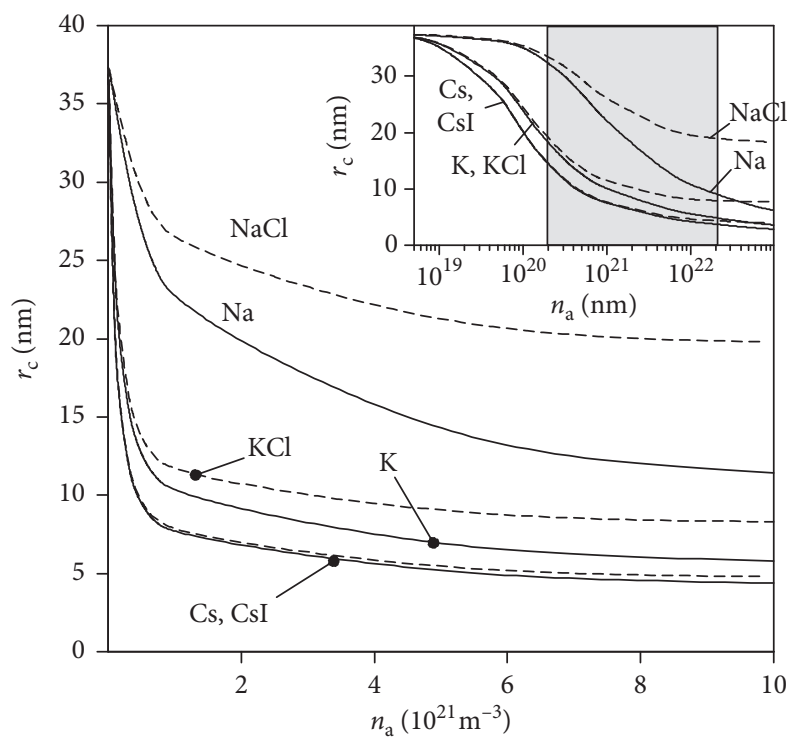

(a)

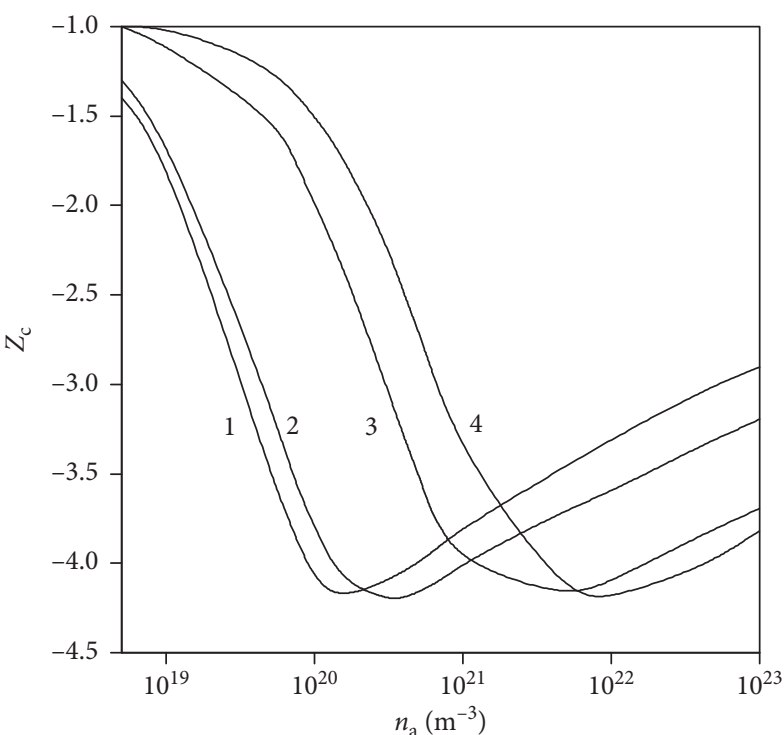

(b)

Figure 4: Dependence of the particle radius of $\mathrm{Al}_{2} \mathrm{O}_{3}$ (a) and the average particle charge (b) on the concentration of additives' atoms (1, Cs; $2, \mathrm{~K} ; 3, \mathrm{Na} ; 4, \mathrm{Li})\left(T=3200 \mathrm{~K}, n_{\mathrm{Al}}=0.5 \cdot 10^{22} \mathrm{~m}^{-3}\right)$. Grey area in (a) covers the concentration range that was experimentally studied in [19].

neutral atoms, $n_{\mathrm{n}}=P_{\mathrm{n}} /\left(k_{B} T_{\mathrm{g}}\right)$ is the concentration of neutral atoms in plasma, and $P_{\mathrm{n}}$ is the partial pressure of neutral gas atoms.

Let us estimate the concentrations of ions in the flame, at which the influence of ion wind becomes dominant. For the experimental data shown in Figure 1, the minimum particle sizes for the additives $\mathrm{K}_{2} \mathrm{CO}_{3}, \mathrm{KCl}$, and CsI were observed $[19,20]$ at the concentration of alkali metal molecules $n_{\mathrm{a}}=$ $1.45 \cdot 10^{21}, 3.0 \cdot 10^{20}$, and $2.6 \cdot 10^{20} \mathrm{~m}^{-3}$, respectively. The ion concentration in the flame can be estimated using the first 


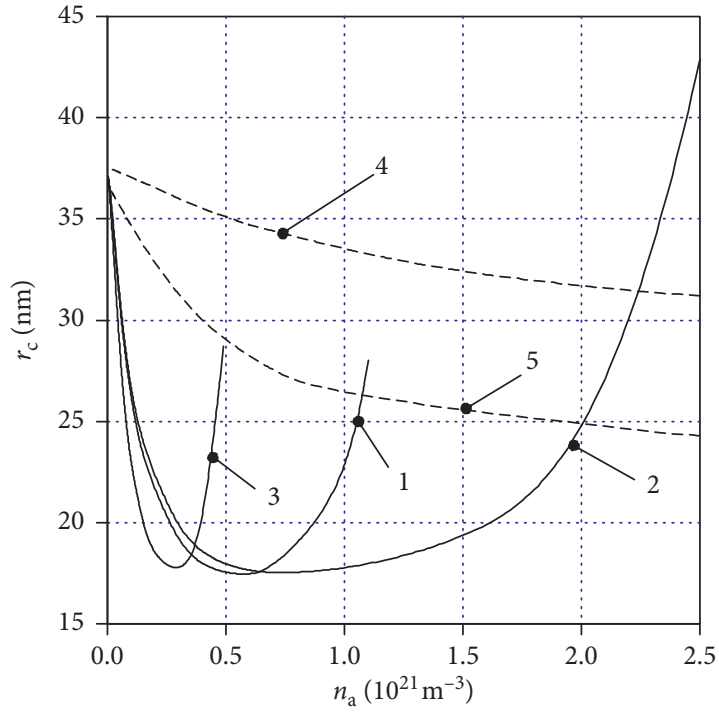

Figure 5: Dependence of the particle radius of $\mathrm{Al}_{2} \mathrm{O}_{3}$ on the concentration of additives' atoms for a monodisperse aerosol taking into account the polarization interaction of $\mathrm{Al}_{2} \mathrm{O}_{3}$ particles $\left(T=3200 \mathrm{~K}, n_{\mathrm{Al}}=0.5 \cdot 10^{22} \mathrm{~m}^{-3}\right) .1, \mathrm{~K}_{2} \mathrm{CO}_{3} ; 2, \mathrm{KCl} ; 3$, CsI; 4, LiCl; 5 , $\mathrm{NaCl}$.

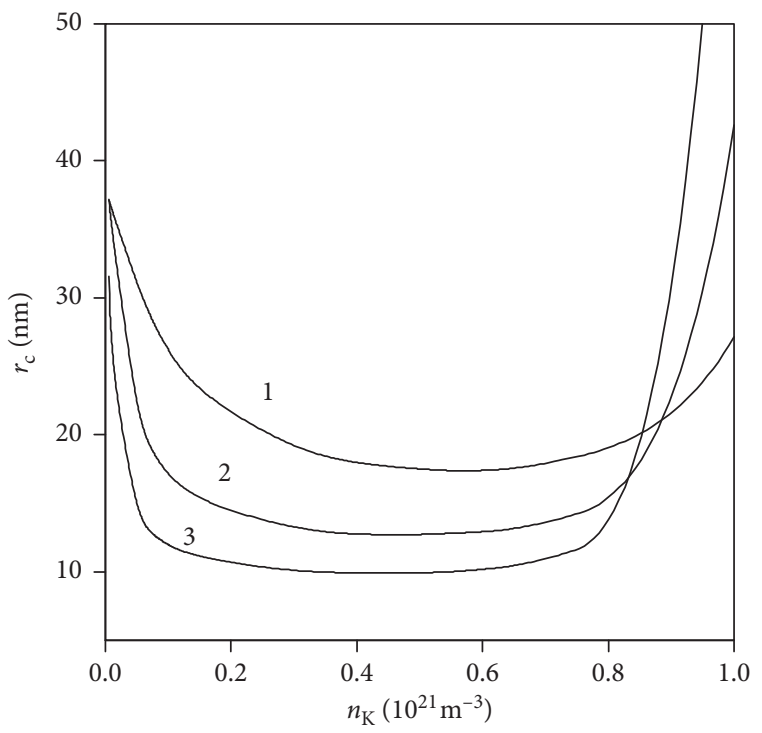

Figure 6: Dependence of the particle radius of $\mathrm{Al}_{2} \mathrm{O}_{3}$ on the concentration of potassium atoms at different temperatures. 1, $T_{\mathrm{g}}=3200 \mathrm{~K}, n_{\mathrm{Al}}=5 \cdot 10^{21} \mathrm{~m}^{-3} ; 2, T_{\mathrm{g}}=3000 \mathrm{~K}, n_{\mathrm{Al}}=1.3 \cdot 10^{21} \mathrm{~m}^{-3} ; 3$, $T_{\mathrm{g}}=2800 \mathrm{~K}, n_{\mathrm{Al}}=4.9 \cdot 10^{20} \mathrm{~m}^{-3}$.

equation of system (5) under the assumption that $n_{\mathrm{e}} \approx n_{\mathrm{i}}$. The concentration of ions of the additive in this case is determined by the positive root of the quadratic equation: $n_{\mathrm{i}}=(1 / 2) K\left(\sqrt{1+\left(4 n_{\mathrm{e}} / K\right)}-1\right)$, where $K=2\left(\left(m_{\mathrm{e}} k_{B} T_{\mathrm{g}}\right) /\right.$ $\left.\left(2 \pi \hbar^{2}\right)\right)^{3 / 2} \exp \left(-\left(/\left(k_{B} T_{\mathrm{g}}\right)\right)\right)$ and for $\mathrm{K}_{2} \mathrm{CO}_{3}, \mathrm{KCl}$, and CsI is $n_{\mathrm{i}} \sim 3.7 \cdot 10^{20}, 1.4 \cdot 10^{20}$, and $2.0 \cdot 10^{20} \mathrm{~m}^{-3}$, respectively. These estimates are in a good agreement with the results of calculations, which show that for these additives the increase in the coagulation rate begins with ion concentrations $n_{\mathrm{i}}>(2 \div 4) \cdot 10^{20} \mathrm{~m}^{-3}$. At the same time, for $\mathrm{NaCl}$ and $\mathrm{LiCl}$ additives, such values of $n_{\mathrm{i}}$ are not reached even at very high concentrations of additives' atoms $\left(n_{\mathrm{a}} \sim 5 \cdot 10^{23} \mathrm{~m}^{-3}\right)$.

For the additives of alkali metal atoms, the attainment of a certain ion concentration $\left(n_{\mathrm{i}}>10^{20} \mathrm{~m}^{-3}\right)$, above which the charged particle coagulation rate begins to increase, results in limiting the range of $\mathrm{Al}_{2} \mathrm{O}_{3}$ particle size control. In practice, it was possible to obtain a fivefold decrease in the average particle size [19], while the analysis given above predicts the possibility of a tenfold reduction in size.

A possible way to overcome this limitation is to use the elements for the flame ionization that have a high affinity for electrons, for example, chlorine atoms. The main mechanism of charging $\mathrm{Al}_{2} \mathrm{O}_{3}$ particles in such plasma is thermionic emission. Atoms of chlorine capture thermoelectrons from the gas phase and become negative ions. The results of calculations of the ionization equilibrium in such systems are shown in Figure 7. At low concentrations of chlorine atoms, their capture of electrons has practically no effect on the concentration of electrons in the thermionic plasma (curve 3 ) and the particle size of aluminum oxide (curve 1). An increase in the concentration of chlorine atoms leads to an increase in the concentration of chloride ions (curve 2). This increase is due to the capture of electrons by chlorine atoms, so the concentration of electrons in the plasma decreases. According to (4), a decrease in $n_{\mathrm{e}}$ leads to an increase in the positive particle charge and, consequently, to a decrease in the coagulation rate and the particle size.

It is easy to see that there is a physical limit of the concentration of ions of electronegative gases. Their concentration cannot be higher than the concentration of electrons in the gas phase $\left(n_{\mathrm{e}}\right)$. The electron concentration in the thermionic plasma cannot exceed the concentration of electrons on the particle surface $\left(n_{\mathrm{es}}\right)$. For aluminum oxide $(W=4.7 \mathrm{eV})$ at $T_{\mathrm{g}}=3200 \mathrm{~K}$, concentration value is $n_{\mathrm{es}} \approx 3.5 \cdot 10^{19} \mathrm{~m}^{-3}$. According to Figure 7 (curve 2), the value of $n_{\mathrm{Cl}}^{-} \approx n_{\mathrm{es}}$ is reached at the chlorine concentration of $n_{\mathrm{Cl}} \sim 10^{23} \mathrm{~m}^{-3}$ (the mole fraction of chlorine atoms in the gas phase is about $4-5 \%$ ) and cannot be increased by a further increase in the concentration of chlorine atoms in the flame. The value $n_{\mathrm{Cl}}^{-}$is less than the limiting concentration of ions in the plasma $\left(n_{\mathrm{i}}>10^{20} \mathrm{~m}^{-3}\right)$, at which the ion drag forces of particles begin to predominate over the forces of their Coulomb repulsion.

\section{Conclusions}

The presented studies have shown that the thermal ionization of the combustion zone of a dust flame of aluminum particles plays an important, possibly determining, role in the formation and growth of condensed $\mathrm{Al}_{2} \mathrm{O}_{3}$ particles. The results of the study allow us to indicate the ability to control the composition and properties of complex plasma opens wide opportunities for efficient control of dispersive properties of alumina nanoparticles obtained by combustion technique.

It was shown that in the case of flame ionization by the additives of atoms of easily ionizable elements, the 


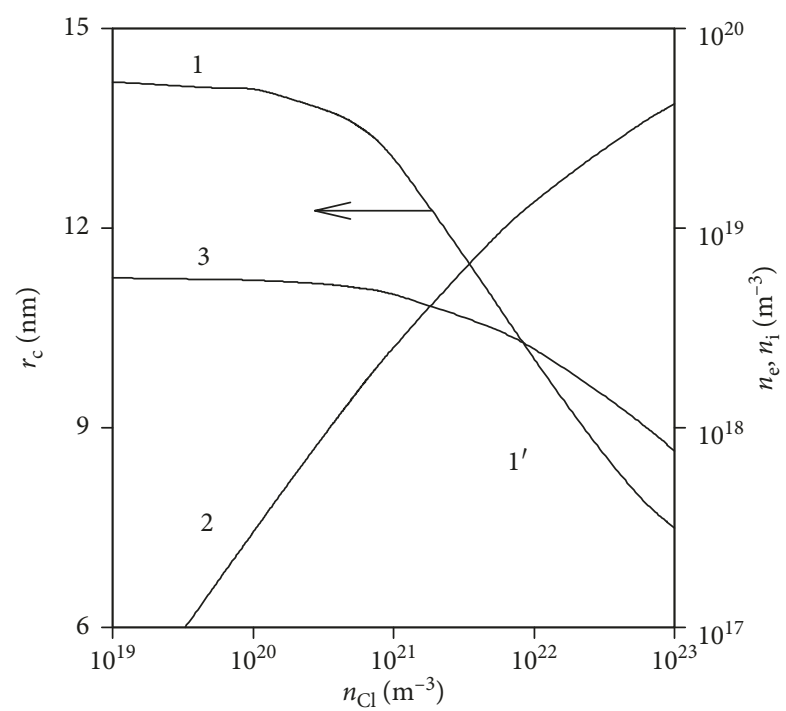

Figure 7: Dependences of the concentrations of electrons, chloride ions, and the radius of $\mathrm{Al}_{2} \mathrm{O}_{3}$ particles in the microflame of an aluminum particle on the concentration of chlorine atoms $\left(C_{\mathrm{f}}=0.4 \mathrm{~kg} / \mathrm{m}^{3}, T_{\mathrm{g}}=3200 \mathrm{~K} .1\right.$, the particle radius of $\mathrm{Al}_{2} \mathrm{O}_{3}\left(r_{\mathrm{c}}\right) ; 2$, the concentration of chloride ions $\left(n_{\mathrm{Cl}}^{-}\right) ; 3$, the electron concentration $\left(n_{\mathrm{e}}\right)$.

concentration of these atoms is an effective control parameter, the variation of which can provide opposite effects on particle size. The atoms of alkali metals ( $\mathrm{K}$ and $\mathrm{Cs}$ ) at low concentrations lead to a sharp decrease in the coagulation rate and a decrease in the characteristic size of alumina nanoparticles, and at higher additives' concentrations, to a rapid coagulation of the ionized aerosol. For the alkali metal atoms with higher ionization potentials ( $\mathrm{Li}$ and $\mathrm{Na}$ ) than for $\mathrm{K}$ and $\mathrm{Cs}$, the variation of the additives' concentration leads to a relatively weak monotonic dependence of the particle size on the additives' concentration, for which the ion drag of particles does not become dominant at any concentration of $\mathrm{Li}$ and $\mathrm{Na}$ atoms. For potassium and cesium salts ( $\mathrm{KCl}$ and $\mathrm{CsI}$ ), the constituent atoms of electronegative gases $(\mathrm{Cl}$ and $\mathrm{I})$ have a weak effect on the ionization equilibrium in the flame and on the particle size of $\mathrm{Al}_{2} \mathrm{O}_{3}$. The authors argue that the proposed model of coagulation in the microflame will help evaluate the suitability of a chemical compound for its use as an additive to aluminum in order to control the distribution of GDS products.

The possibility of accelerating or slowing the rate of coagulation of particles in a microflame provides important practical applications. For the GDS method of alumina nanoparticles, the coagulation inhibition mode is desirable, since it allows finely adjusting the size of the synthesized particles in the range $r_{\mathrm{c}}=8 \div 50 \mathrm{~nm}$. On the other hand, in order to purify the gas phase from fine particles in some technological processes, it is desirable to work in a fast (explosive) coagulation mode. To transfer coagulation to this regime, it is necessary to use additives with a low ionization potential ( $\mathrm{K}$ and $\mathrm{Cs}$ ), which can provide the concentration of ions in the flame of $n_{\mathrm{i}}>10^{20} \mathrm{~m}^{-3}$. To expand the range of the size of GDS nanoparticles of aluminum oxide in a region of small dimensions, it may be prospective to use the additives of electronegative gases $\left(a_{\mathrm{s}}>1 \%\right)$ with the high energy of electron affinity.

\section{Data Availability}

The experimental particle distribution data used to support the findings of this study are available from the corresponding author upon request.

\section{Conflicts of Interest}

The authors declare that they have no conflicts of interest.

\section{Acknowledgments}

This article was written with financial support from the Ministry of Education and Science of Ukraine. We thank our cooperator, Ekaterina Khanchich, for her help in translating and preparing the article.

\section{References}

[1] E. W. Price and R. K. Sigman, "Combustion of aluminized solid propellants," Progress in Astronautics and Aeronautics, vol. 185, pp. 663-687, 2000.

[2] E. I. Shkolnikov, A. Z. Zhuk, and M. S. Vlaskin, "Aluminum as energy carrier: feasibility analysis and current technologies overview," Renewable and Sustainable Energy Reviews, vol. 15, no. 9, pp. 4611-4623, 2011.

[3] J. M. Bergthorson, S. Goroshin, M. J. Soo et al., "Direct combustion of recyclable metal fuels for zero-carbon heat and power," Applied Energy, vol. 160, pp. 368-382, 2015.

[4] A. N. Zolotko, Y. I. Vovchuk, N. I. Poletayev, A. V. Florko, and I. S. Al'tman, "Synthesis of nanooxides in two-phase laminar flames," Combustion, Explosion, and Shock Waves, vol. 32, no. 3, pp. 262-269, 1996.

[5] A. N. Zolotko, N. I. Poletaev, and Y. I. Vovchuk, "Gas-disperse synthesis of metal oxide particles," Combustion, Explosion, and Shock Waves, vol. 51, no. 2, pp. 252-268, 2015.

[6] N. I. Poletaev, A. N. Zolotko, and Y. A. Doroshenko, "Degree of dispersion of metal combustion products in a laminar dust flame," Combustion, Explosion, and Shock Waves, vol. 47, no. 2, pp. 153-165, 2011.

[7] Y. Xing and D. E. Rosner, "Prediction of spherule size in gas phase nanoparticles synthesis," Journal of Nanoparticle Research, vol. 1, no. 2, pp. 277-291, 1999.

[8] M. W. Beckstead, Y. Liang, and K. V. Pudduppakkam, "Numerical simulation of single aluminum particle combustion (review)," Combustion, Explosion, and Shock Waves, vol. 41, no. 6, pp. 622-638, 2005.

[9] S. R. Desai, H. Wu, C. M. Rohlfing, and L.-S. Wang, "A study of the structure and bonding of small aluminum oxide clusters by photoelectron spectroscopy: $\mathrm{Al}_{x} \mathrm{O}_{y}{ }^{-}(x=1-2, y=1-5)$," Journal of Chemical Physics, vol. 106, no. 4, pp. 1309-1317, 1997.

[10] A. M. Savel'ev and A. M. Starik, "The formation of $\left(\mathrm{Al}_{2} \mathrm{O}_{3}\right)_{n}$ clusters as a probable mechanism of aluminum oxide nucleation during the combustion of aluminized fuels: numerical analysis," Combustion and Flame, vol. 196, pp. 223-236, 2018.

[11] V. M. Gremyachkin, A. G. Istratov, and O. I. Leipunskii, "Formation of condensed oxide particles by combustion of 
metal droplets," Journal of Applied Mechanics and Technical Physics, vol. 15, no. 4, pp. 494-499, 1974.

[12] N. I. Poletaev, "Formation of condensed combustion products in metal dust flames: nucleation stage," Combustion, Explosion, and Shock Waves, vol. 51, no. 3, pp. 299-312, 2015.

[13] G. D. Ulrich, "Special report," Chemical \& Engineering News, vol. 62, no. 32, pp. 22-29, 1984.

[14] J. J. Helble, "Combustion aerosol synthesis of nanoscale ceramic powders," Journal of Aerosol Science, vol. 29, no. 5-6, pp. 721-736, 1998.

[15] H. K. Kammler, L. Mädler, and S. E. Pratsinis, "Flame synthesis of nanoparticles," Chemical Engineering \& Technology, vol. 24 , no. 6 , pp. 583-596, 2001.

[16] N. I. Poletaev, "Firmation of condensed combustion products in dust flames of metals: coagulation stage," Combustion, Explosion, and Shock Waves, vol. 51, no. 4, pp. 444-456, 2015.

[17] O. G. Glotov, A. A. Onishchuk, V. V. Karasev et al., "The size and morphology of nanooxide aerosol formed during aluminum particle combustion," Doklady Physical Chemistry, vol. 412, no. 2, pp. 206-209, 2007.

[18] D. A. Yagodnikov and E. I. Gusachenko, "Experimental study of the disperse composition of condensed products of aluminum particle combustion in air," Combustion, Explosion, and Shock Waves, vol. 40, no. 2, pp. 154-162, 2004.

[19] N. I. Poletaev and Y. A. Doroshenko, "Effect of addition of potassium carbonate to aluminum powder on the grain size of $\mathrm{Al}_{2} \mathrm{O}_{3}$ nanoparticles formed in the laminar dusty flame," Combustion, Explosion, and Shock Waves, vol. 49, no. 1, pp. 26-37, 2013.

[20] N. I. Poletaev, A. N. Zolotko, Y. A. Doroshenko et al., "Smoky plasma in a dust flame," Ukrainian Journal of Physics, vol. 59, no. 4, pp. 379-384, 2014.

[21] B. S. Haynes, H. Jander, and H. G. Wagner, "The effect of metal additives on the formation of soot in premixed flames," Symposium (International) on Combustion, vol. 17, no. 1, pp. 1365-1374, 1978.

[22] Y. Xiong, S. E. Pratsinis, and S. V. R. Mastrangelo, "The effect of ionic additives on aerosol coagulation," Journal of Colloid and Interface Science, vol. 153, no. 1, pp. 106-117, 1992.

[23] T. Fujimoto, Y. Kuga, S. E. Pratsinis, and K. Okuyama, "Unipolar ion charging and coagulation during aerosol formation by chemical reaction," Powder Technology, vol. 135136, pp. 321-335, 2003.

[24] M. Smith, K. Lee, and T. Matsoukas, "Coagulation of charged aerosols," Journal of Nanoparticle Research, vol. 1, no. 2, pp. 185-195, 1999.

[25] N. I. Poletaev and A. V. Florko, "Spectral studies of the gas component of an aluminum dust flame," Combustion, Explosion, and Shock Waves, vol. 44, no. 4, pp. 437-443, 2008.

[26] N. D. Ageev, Y. I. Vovchuk, S. V. Goroshin, A. N. Zolotko, and N. I. Poletaev, "Steady combustion of solid fuel gas-suspensions. Laminar diffusion two-phase flame," Combustion, Explosion, and Shock Waves, vol. 26, no. 6, pp. 669-677, 1990.

[27] N. I. Poletaev and Y. I. Vovchuk, "Particularities of the laminar diffusion dust flames," in Proceedings of the International Conference on Combustion and Detonation, Moscow, Russia, August 2004.

[28] N. I. Poletaev and A. V. Florko, "Radiative characteristics of an aluminum dust flame. condensed phase," Combustion, Explosion, and Shock Waves, vol. 43, no. 4, pp. 414-422, 2007.

[29] Y. A. Doroshenko, N. I. Poletaev, and V. I. Vishnyakov, "Dispersion of dust sizes in the plasma of aluminum dust flame," Physics of Plasmas, vol. 16, no. 9, article 094504, 2009.
[30] M. W. Chase, NIST-JANAF Thermochemical Tables, American Chemical Society and the American Institute of Physics for the National Institute of Standards and Technology, New York, NY, USA, 4th edition, 1998.

[31] Y. Huang, G. A. Risha, V. Yang, and R. A. Yetter, "Effect of particle size on combustion of aluminum particle dust in air," Combustion and Flame, vol. 156, no. 1, pp. 5-13, 2009.

[32] Y. B. Zeldovich, "On the theory of combustion of nonpremixed gases," Technical Physics, vol. 19, no. 10, pp. 11991210, 1949.

[33] M. A. Olevanov, Y. A. Mankelevich, and T. V. Rakhimova, "Mechanisms of coagulation and growth of dust particles in the low-temperature plasma," Journal of Experimental and Theoretical Physics, vol. 125, no. 2, pp. 324-344, 2004.

[34] T. Matsoukas, "The coagulation rate of charged aerosols in ionized gases," Journal of Colloid and Interface Science, vol. 187, no. 2, pp. 474-483, 1997.

[35] D. R. Lide, CRC Handbook of Chemistry and Physics, Taylor \& Francis Group, Boca Raton, FL, USA, 86th edition, 2005.

[36] B. M. Smirnov, "Cluster plasma," Uspekhi Fizicheskih Nauk, vol. 170, no. 5, pp. 495-534, 2000.

[37] A. M. Ignatov, "Quasigravitation in dusty plasma," Uspekhi Fizicheskih Nauk, vol. 171, no. 2, pp. 213-217, 2001.

[38] V. N. Tsytovich, "The development of physical ideas concerning the interaction of plasma flows and electrostatic fields in dusty plasmas," Uspekhi Fizicheskih Nauk, vol. 177, no. 4, pp. 427-472, 2007.

[39] V. N. Tsytovich and G. E. Morfill, "Collective attraction of like-charged dust particles in the plasma," Fizika Plazmy, vol. 28, no. 3, pp. 195-201, 2002.

[40] S. A. Maiorov, "Effect of bound ions on screening and friction force in the dusty plasma," Fizika Plazmy, vol. 31, no. 8, pp. 749-759, 2005.

[41] B. G. Trusov, "TERRA computer system for modeling phase and chemical equilibrium," in Proceedings of the XIV International Conference on Chemical Thermodynamics, St. Petersburg, Russia, July 2002. 

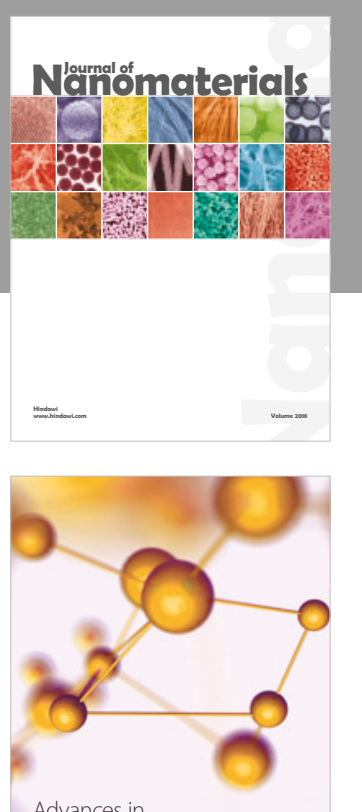

Physical Chemistry
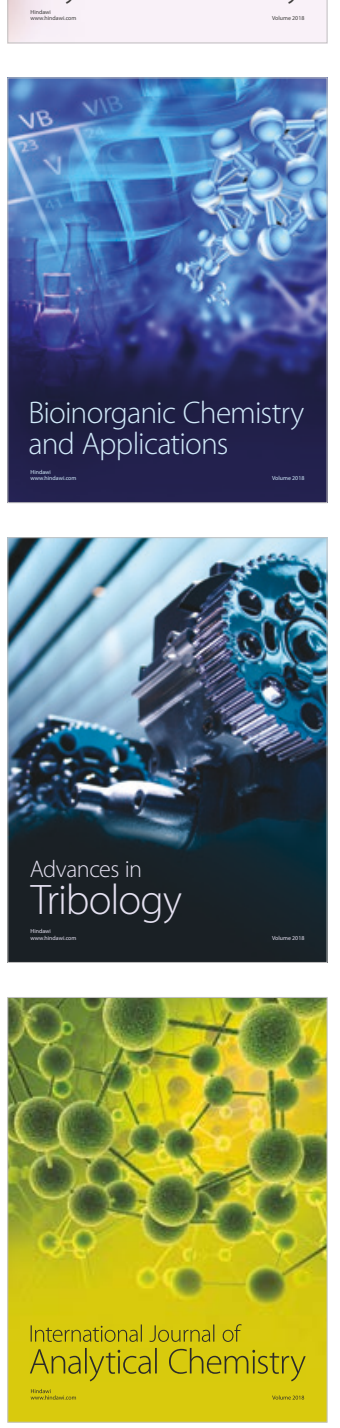

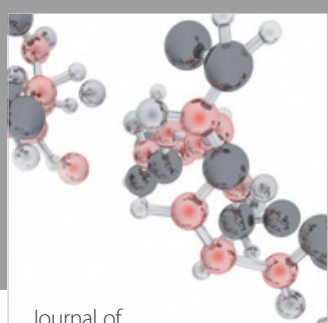

Analytical Methods

in Chemistry

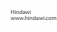

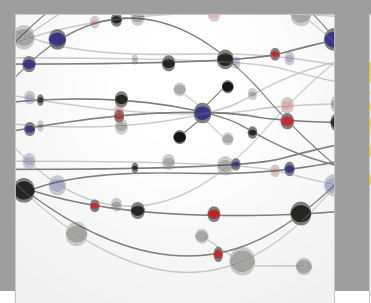

The Scientific World Journal

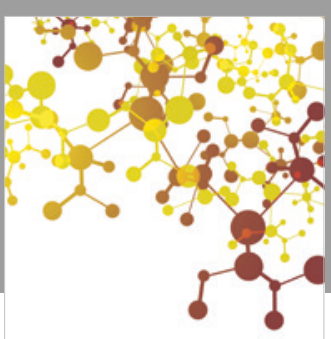

Journal of

Applied Chemistry
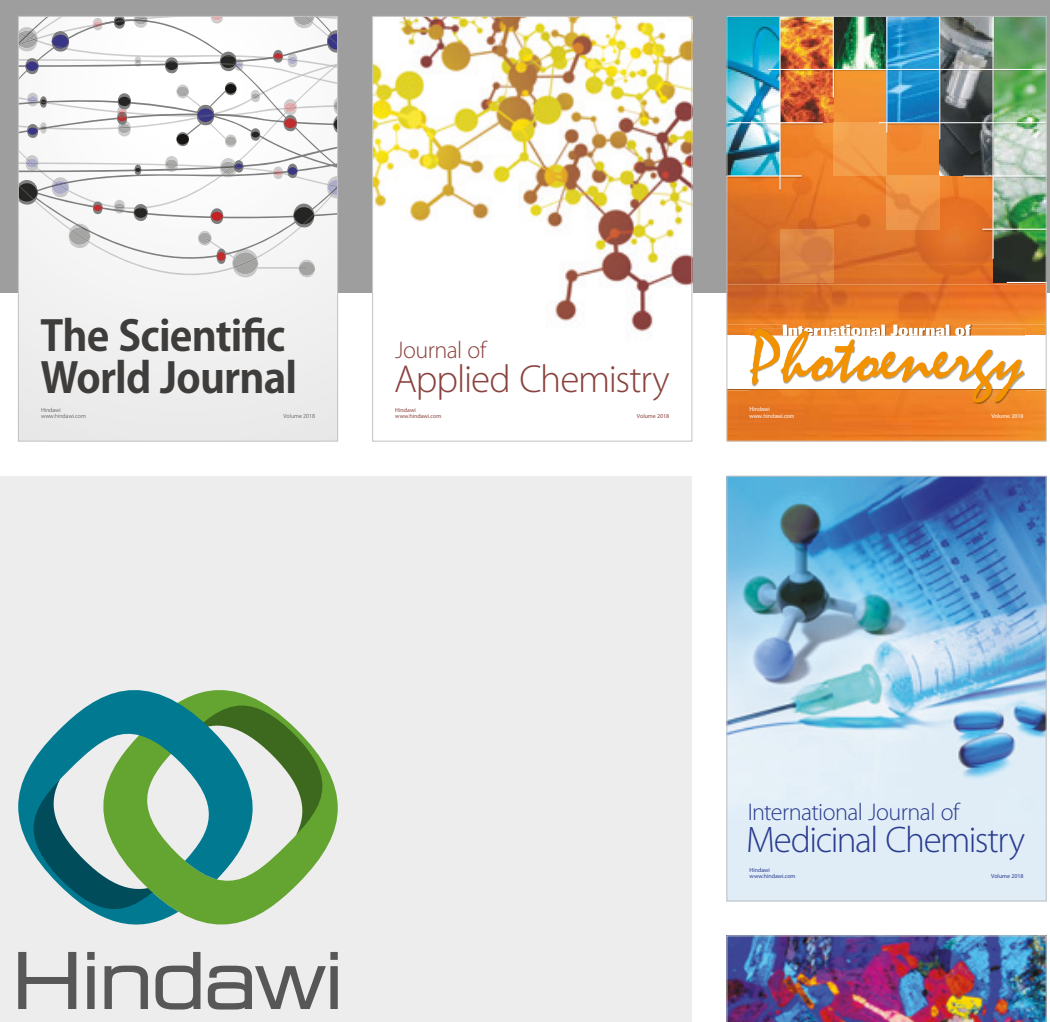

Submit your manuscripts at

www.hindawi.com
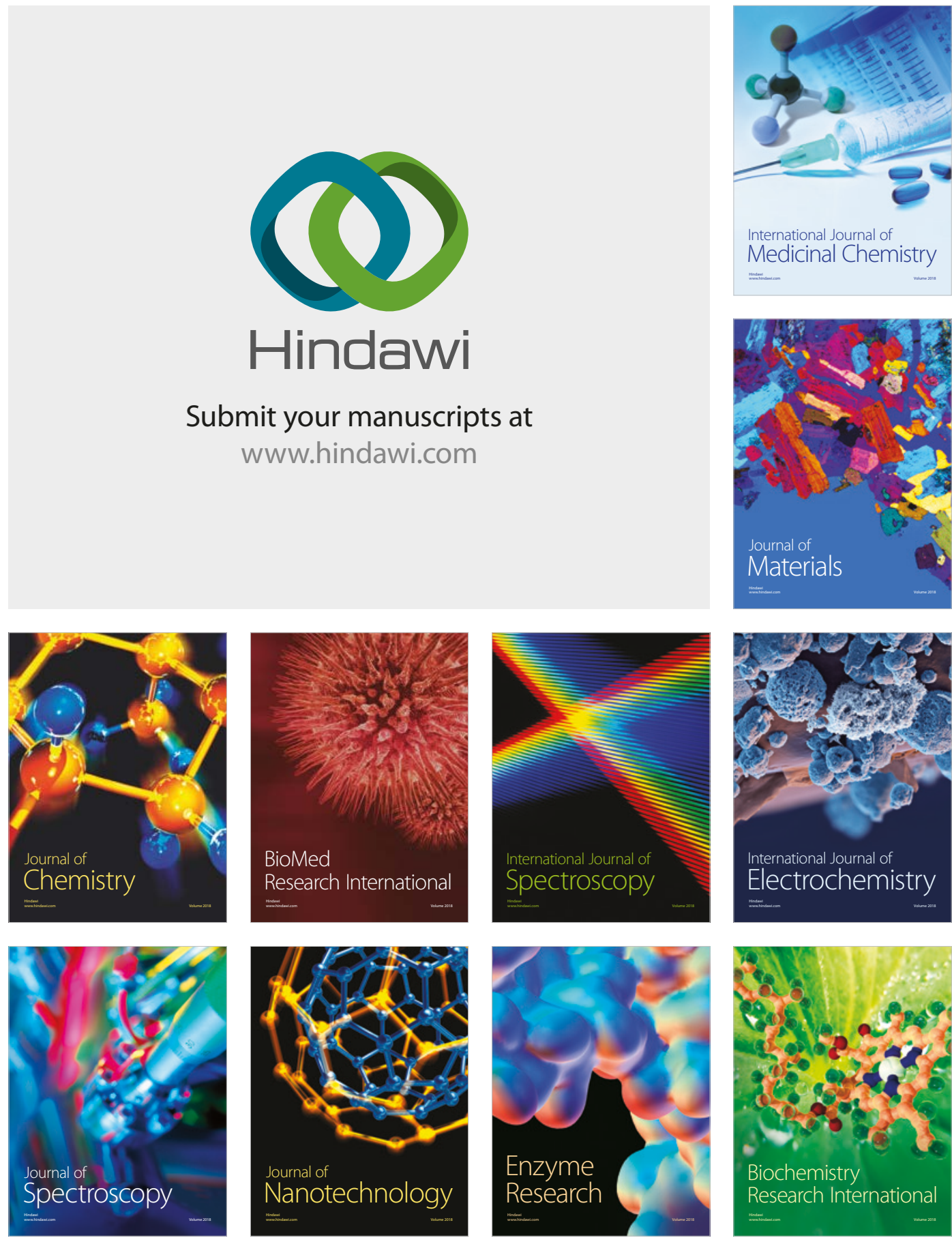
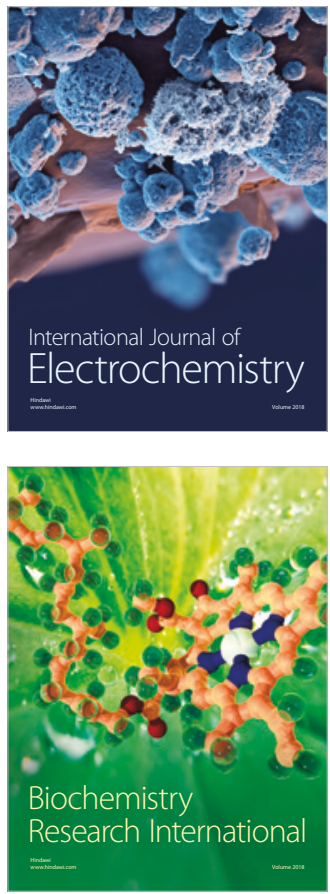